\title{
Evaluating the potential energy savings of an urban Green Infrastructure through environmental simulation
}

\author{
Massimo Palme ${ }^{1}$, Daniele La Rosa ${ }^{2}$, Riccardo Privitera ${ }^{2}$, Giacomo Chiesa ${ }^{3}$ \\ ${ }^{1}$ Universidad Católica del Norte, Escuela de Arquitectura, Antofagasta, Chile \\ ${ }^{2}$ University of Catania, DICAR, Italy \\ ${ }^{3}$ Polytechnical University Turin, DAD, Italy
}

\begin{abstract}
Green infrastructure is a very important aspect to be considered in designing and preparing cities to adapt and mitigate climate change impacts on the built environment. Green based solutions have a strong impact on many aspects, such as controlling storm-water, reducing urban heat island effect, stabilizing soils, facing earthquakes, etcetera. In this paper an environmental analysis is performed by simulation with TRNSYS Studio tool. The cooling potential that can be obtained by trees in residential compounds is assessed, considering shadowing effect, changes in air movement, sky view factor reduction and other simulation-parameter changes. Results show that a reduction of 30 to $50 \%$ in cooling demand can be obtained by using a raw of trees on South, East and especially West façades. Two types of trees are tested, showing different cooling performances depending on the height and form of the trees.
\end{abstract}

\section{Introduction}

In cities, Green infrastructure (GI) is a network of different ecological systems -both natural or artificialthat can be implemented at different spatial scales and are able to provide a wide set of services (Tzoulas et al., 2007) with particular reference to the well-being of citizens and residents. Such services include $\mathrm{CO}_{2}$ sequestration, production of $\mathrm{O}_{2}$, reduction of air pollutants and noise, regulation of microclimate and heat island effect, flood damage reduction, filtering water, pollination and supply of recreational value, and play a fundamental role in health, well-being, and social safety (Pappalardo et al., 2017). GI includes many ecosystems: urban parks and woodland, lakes, streams and rivers, different type of urban greenery, agricultural areas and other more artificial urban features such as green roofs (Wild et al., 2018).

The objective of maintaining and -if possible- increasing GI is thus of growing interest for cities and different urban policies have been developed in the last years (Nesshover et al., 2017): including GI in the built environment, can increase the overall liveability of cities, regenerate deprived districts through urban regeneration programs, improve mental and physical health and quality of life for citizens, reduce urban violence, and decrease social tensions through better social cohesion (Fan et al., 2018).
A great role for more liveable and healthy cities is played by urban vegetation, able to provide beneficial microclimatic effects, including air temperature reduction, which eases the urban heat island effect. The microclimatic benefits of urban vegetation are derived by different processes (Givoni, 1991):

- solar heat gains on windows, walls, roofs, and urban surfaces, including human bodies, are lowered through shading;

- the buildings' long-wave exchanges are reduced at lower surface temperatures through shading;

- the dry-bulb temperatures are lowered through evapotranspiration processes;

- latent cooling is increased due to the addition of moisture to the air through evapotranspiration;

- changes in temperature produced by shadows can generate an increase in the air movement by natural convection.

Micro-climate effects of vegetation have relevant positive impacts on energy demand of buildings. Different studies confirmed the importance of trees shading on the reduction of building cooling energy demand. The positive effect depends on the multiple different configuration among urban environments, land-use configurations, and micro-climate conditions (Calcerano and Martinelli, 2016; Balogun et al., 2014). Economic savings from tree shading are confirmed in different climate conditions and type of buildings (Laband and Sophocleus, 2009; Palme et al., 2017), with performances that can be further increased by the evapotranspiration effect (Konarska et al. 2015; Hsieh et al., 2018)

Different approaches and models have been developed for evaluating the potentiality of trees on cooling energy reduction, but only few works are focused on the different relations between buildings and trees in the urban environment. Assessing the expected cooling effect that can be obtained with different configurations of new greenery represents an important phase to quantify the potential of a GI and therefore deliver urban planning indications toward cities more resilient to climate change impacts. To this end, this paper explores some configurations of greenery located at different orientations around buildings, to quantify and compare energy savings that can be obtained by the considered scenarios. 


\section{Methods}

In this paper we will focus on a case study located in the metropolitan area of Catania, the largest in Sicily, with a total population of more than 700,000. In this area, one of the most typical building pattern is given by regular and irregular blocks composed of different compounds, defined as gated residential units of buildings and shared open spaces (Privitera and La Rosa, 2018), such as open setback yards sidewalks, parking lots, or small urban gardens (figure 1). Different spatial combinations of these features can produce varied energy savings according to the morphological layouts and built-up density of the compounds. These shared open spaces within each compound can be therefore used to develop a GI.

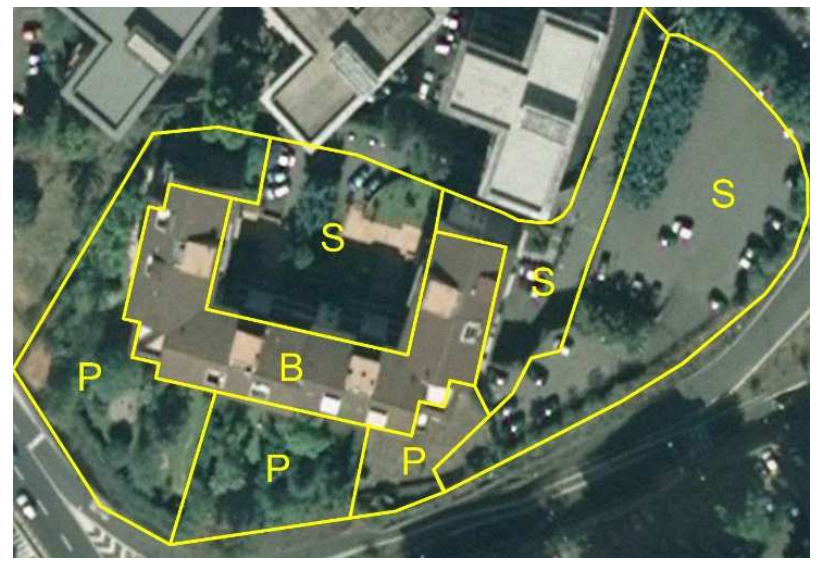

Figure 1: Example of residential compound with open spaces $(B=$ building, $P=$ private open space, $S=$ shared open space).

In this research, seven trees configurations have been considered, surrounding a simple test building of two storeys, E-W oriented. Two trees types have been considered, Pinus Pinaster and Quercus Ilex. Pinus Pinaster have an height of 10 meters while Qurecus Ilex have an height of 6 meters. The rows of trees are 5 meters from the building and are composed by three trees on South orientation and five trees on East and West orientations.
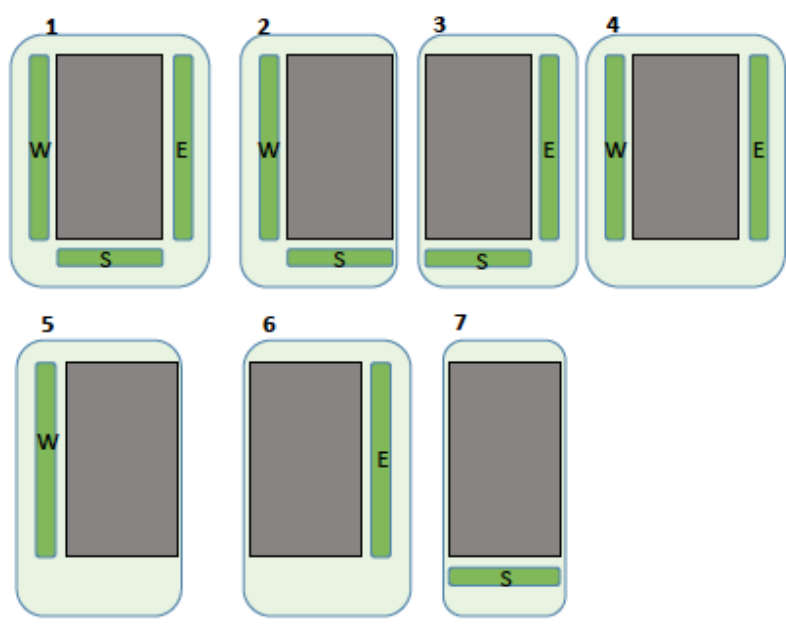

Figure 2: Configurations of trees tested
Trees global effect on building energy demand is simulated taking into account different specific effects of the trees:

- shadows produced on the façade;

- shadows produced on the roof;

- reduction of the sky view factor of the façade;

- reduction of the sky view factor of the roof;

- reduction of the convective coefficient of the façade;

- reduction of the convective coefficient of the roof;

- changes in air renovation of each apartment (ACH).

Some of these effects are positive in summer and negative in winter or vice-versa. ACH refers to nocturnal ventilation in summer season.

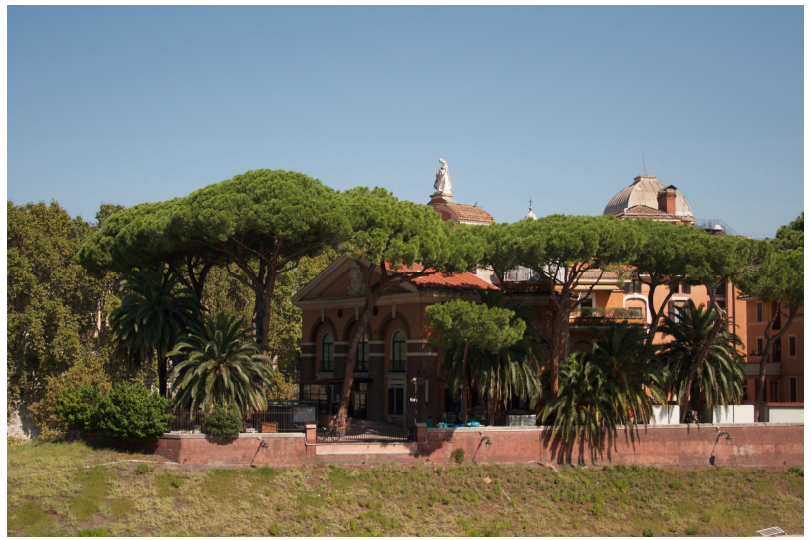

Figure 3: Pinus Pinaster shadow effect

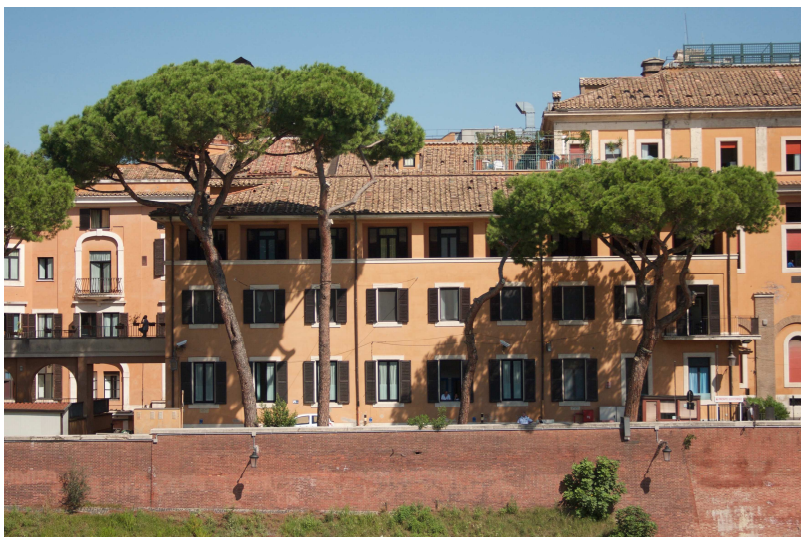

Figure 4: shadows on the façades generated by trees

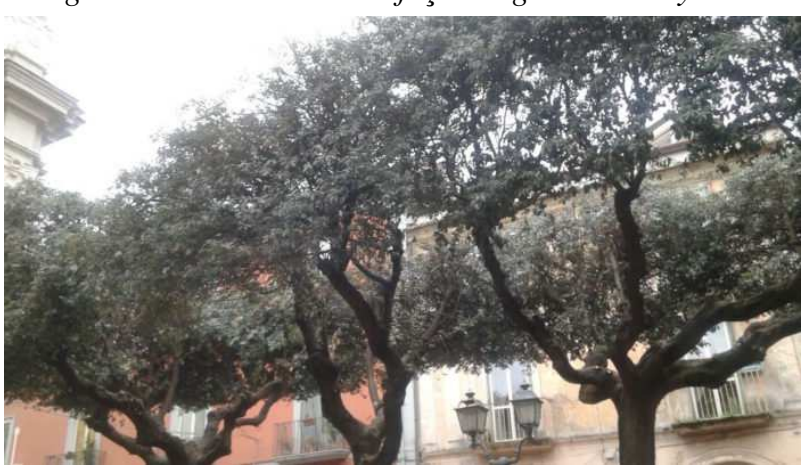

Figure 5: Quercus Ilex shadow effect (source: https://www.ambienteambienti.com/vieste-lecciocultura-del-paesaggio/) 


\section{Climatic emplacement}

Catania is placed in a Mediterranean climatic environment (Koppen classification Csa - temperate climate with hot-dry summer). Figures 6 and 7 show temperature and relative humidity for typical winter and summer days.

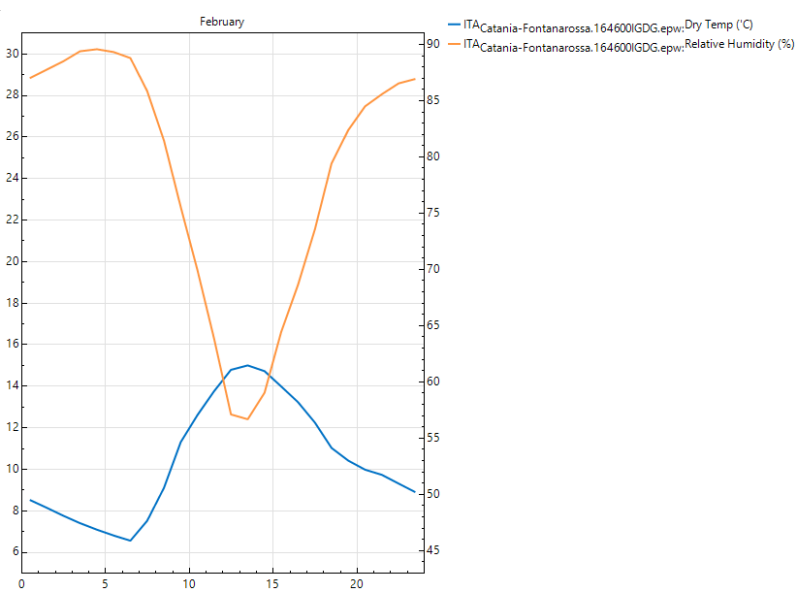

Figure 6: dry bulb temperature and relative humidity in February

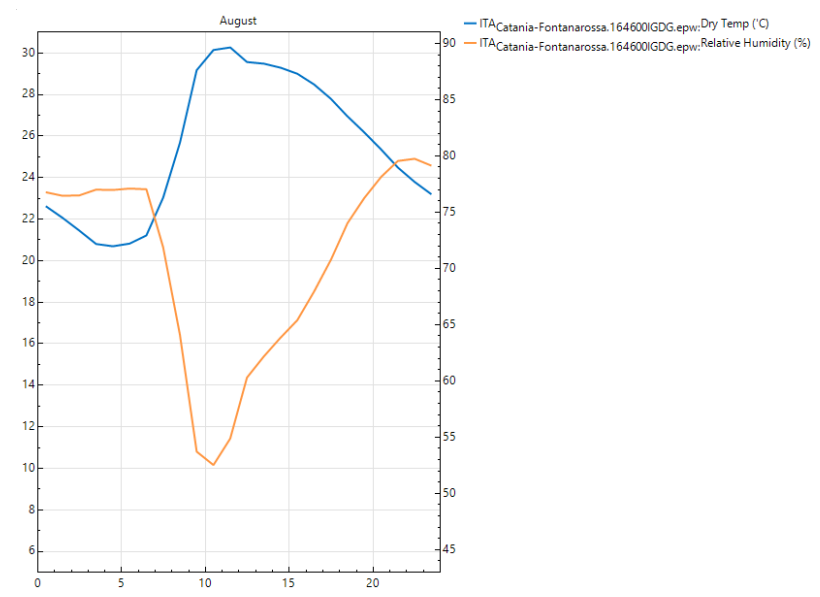

Figure 7: dry bulb temperature relative humidity in August

\section{Simulation parameters}

The test building is a two-storeys residential building with a floor area of $200 \mathrm{~m}^{2}$. It is composed by 8 small apartments of $50 \mathrm{~m}^{2}$ each and E-W oriented. Table 1 and 2 resume the envelope and operation parameters used in simulation assuming a typical existing-building configuration.

Table 1: Envelope parameters for building simulation

\begin{tabular}{|l|l|l|l|l|}
\hline & Wall & Roof & Floor & Window \\
\hline $\mathbf{U}\left(\mathbf{W} / \mathbf{m}^{\mathbf{2}} \mathbf{K}\right)$ & 0.66 & 0.61 & 3.18 & 5.8 \\
\hline $\mathbf{h}_{\mathbf{i}}\left(\mathbf{W} / \mathbf{m}^{\mathbf{2}} \mathbf{K}\right)$ & 3 & 5 & 2 & 3 \\
\hline $\mathbf{M}\left(\mathbf{k J} / \mathbf{m}^{3} \mathbf{K}\right)$ & 1300 & 1200 & 1600 & $/$ \\
\hline Solar absorption & 0.6 & 0.5 & 0.5 & $/$ \\
\hline Emissivity & 0.9 & 0.9 & 0.9 & 0.9 \\
\hline g-value & $/$ & $/$ & $/$ & 0.86 \\
\hline
\end{tabular}

Table 2: Operational parameters for building simulation

\begin{tabular}{|l|l|l|l|}
\hline $\begin{array}{l}\text { Heating set } \\
\text { point }\end{array}$ & $\begin{array}{l}\text { Cooling set } \\
\text { point }\end{array}$ & Gains & Lighting \\
\hline $18^{\circ} \mathrm{C}$ & $26^{\circ} \mathrm{C}$ & $5 \mathrm{~W} / \mathrm{m}^{2}$ & $10 \mathrm{~W} / \mathrm{m}^{2}$ \\
\hline $\begin{array}{l}\text { Lighting } \\
\text { schedule }\end{array}$ & $\begin{array}{l}\text { Summer } \\
\text { ventilation }\end{array}$ & Activity & People \\
\hline $18-22$ & $22-6$ & $1 \mathrm{met}$ & $25 \mathrm{~m}^{2} /$ person \\
\hline
\end{tabular}

Reference building has windows of $3 \mathrm{~m}^{2}$ on $\mathrm{W}$ and $\mathrm{E}$ façades and small openings of $0.5 \mathrm{~m}^{2}$ on $\mathrm{N}$ and $\mathrm{S}$ façades. Simulation was carried out using TRNSYS Studio tool (version 17). TRNSYS types used are:

- Type 56, for multy-zone building definition

- Type 31e, for psycometric properties calculation

- Type 69b, for fictive sky temperature calculation

- Type 67, for shadow masks definition

- Type 15-3, for weather data reading in epw format

- Type $65 \mathrm{c}$, for results visualization and writing

\section{Shadows}

To consider shadow effect on façades and roof, a shadow mask is defined in TRNSYS (azimuth and height angles of obstacles for each façade). Solar transmittance of considered trees are obtained by references (Konarska et al. 2014; Cantón et al. 1998; McPearson et al. 2018). Shadow mask is defined considering the distance of 5 meters of the trees from the façade. Table 3 resumes the minimum and maximum inclination and azimuth angles used to simulate the apparent sun movement on the façades.

Table 3: Shadow masks definition

\begin{tabular}{|c|c|c|c|c|}
\hline \multirow{2}{*}{} & \multicolumn{4}{|c|}{ Shadow Masks } \\
\cline { 2 - 5 } & $\begin{array}{c}\text { Pinus } \\
\text { Pinaster 1 }^{\text {st }} \\
\text { floor }\end{array}$ & $\begin{array}{c}\text { Pinus } \\
\text { Pinaster 2d }^{\mathrm{d}} \\
\text { floor }\end{array}$ & $\begin{array}{c}\text { Quercus } \\
\text { Ilex 1 } \\
\text { floor }\end{array}$ & $\begin{array}{c}\text { Quercus } \\
\text { Ilex 2 }{ }^{\mathrm{d}} \text { floor }\end{array}$ \\
\hline $\begin{array}{c}\text { Inclination } \\
\text { angle min } \\
\left({ }^{\circ}\right)\end{array}$ & 45 & 30 & 37 & 0 \\
\hline $\begin{array}{c}\text { Inclination } \\
\text { angle max } \\
\left({ }^{\circ}\right)\end{array}$ & 90 & 90 & 62 & 53 \\
\hline $\begin{array}{c}\text { Azimuth } \\
\text { angle min } \\
\left({ }^{\circ}\right)\end{array}$ & -10 & -10 & -30 & -30 \\
\hline $\begin{array}{c}\text { Azimuth } \\
\text { angle max } \\
\left({ }^{\circ}\right)\end{array}$ & 10 & 10 & 30 & 30 \\
\hline
\end{tabular}

\section{Sky view factors}

Sky view factor also changes because of trees. This effect is in general opposite to the solar radiation shadowing: it is a positive effect in winter and negative in summer. However, in calculation of long-wave exchanges of the buildings' walls, the trees should also be considered as a surface with a temperature very close to the air temperature, this means lower than the pavement or surrounding buildings surfaces (Palme and Salvati, 2018). 
Table 4 shows the solar transmittance and SVF values for seasons and trees typologies.

Table 4: Parameters of trees typologies

\begin{tabular}{|l|c|c|c|c|}
\hline \multirow{2}{*}{} & \multicolumn{2}{|c|}{ Winter } & \multicolumn{2}{c|}{ Summer } \\
\cline { 2 - 5 } & Shadow (\%) & SVF (\%) & Shadow (\%) & SVF (\%) \\
\hline Pinus Pinaster & 88 & 12 & 88 & 12 \\
\hline Quercus Ilex & 55 & 45 & 92 & 8 \\
\hline
\end{tabular}

\section{Convective coefficients}

Convective coefficients of surface thermal exchange are calculated using the following equations (1) and (2):

$$
\begin{aligned}
& h_{c}=2.55 V_{10}+4.47 \\
& h_{c}=2.28 V_{10}+8.18
\end{aligned}
$$

Respectively for horizontal (1) and vertical (2) surfaces (Hagashima and Tanimoto, 2003), where $V_{10}$ is the average value of air speed taken from the weather data file. A reduction in convective coefficients of $25-50 \%$ is supposed for wind-protected façades (by trees) and for the roof in the case of Pinus Pinaster configuration. Table 4 resumes the values of shadows, SVF and convective coefficient of the roofs for Pinus Pinaster cases. Figure 8 shows the roof partition for calculation.

\section{Table 5: Roof's parameters for Pinus Pinaster}

\begin{tabular}{|c|c|c|c|c|c|c|c|c|c|c|c|c|}
\hline & \multicolumn{12}{|c|}{ Roof parameters } \\
\hline & \multicolumn{4}{|c|}{ Shadow $(\%)$} & \multicolumn{4}{|c|}{$\operatorname{SVF}(\%)$} & \multicolumn{4}{|c|}{$\mathrm{h}\left(\mathrm{W} / \mathrm{m}^{2} \mathrm{~K}\right)$} \\
\hline & 1 & 2 & 3 & 4 & 1 & 2 & 3 & 4 & 1 & 2 & 3 & 4 \\
\hline Base & 0 & 0 & 0 & 0 & 100 & 100 & 100 & 100 & 18 & 18 & 18 & 18 \\
\hline C 1 & 22 & 22 & 44 & 44 & 75 & 75 & 50 & 50 & 13 & 13 & 9 & 9 \\
\hline $\mathrm{C} 2$ & 22 & 0 & 22 & 44 & 75 & 100 & 75 & 50 & 13 & 18 & 13 & 9 \\
\hline C 3 & 0 & 22 & 44 & 22 & 100 & 75 & 50 & 75 & 18 & 13 & 9 & 13 \\
\hline $\mathrm{C} 4$ & 22 & 22 & 22 & 22 & 75 & 75 & 75 & 75 & 13 & 13 & 13 & 13 \\
\hline C 5 & 22 & 0 & 0 & 22 & 75 & 100 & 100 & 75 & 13 & 18 & 18 & 13 \\
\hline C 6 & 0 & 22 & 22 & 0 & 100 & 75 & 75 & 100 & 18 & 13 & 13 & 18 \\
\hline C7 & 0 & 0 & 22 & 22 & 100 & 100 & 75 & 75 & 18 & 18 & 13 & 13 \\
\hline
\end{tabular}
configurations

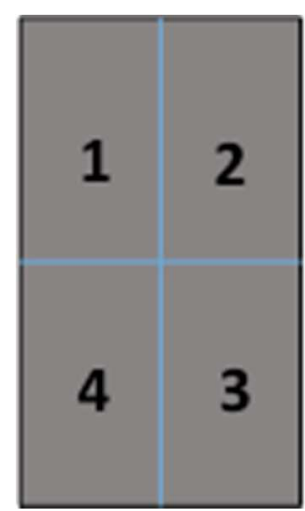

Figure 8: Roof partition for calculation

\section{Air Changes per Hour}

Air Changes per Hour ( $\mathrm{ACH})$ are defined as the number of a space volumes that are been changed in one hour. Infiltration is set to $0.2 \mathrm{ACH}$, while nocturnal ventilation is considered, for this study, to be $1 \mathrm{ACH}$ in the base case for the summer season. A more accurate estimation of this last value could be obtained by using an equation like (3), including a previous analysis on wind velocity at the openings' height and orientations (Grosso, 2011):

$$
q=v \sqrt{\frac{C_{p}^{+}-C_{p}^{-}}{\frac{1}{C_{d 1}^{2} A_{1}^{2}+\frac{1}{C_{d 2}^{2} A_{2}^{2}}+\cdots+\frac{1}{C_{d n}^{2} A_{n}^{2}}}}}
$$

Where $q$ is the airflow $\left[\mathrm{m}^{3} / \mathrm{s}\right], v$ the wind velocity $[\mathrm{m} / \mathrm{s}]$, $\mathrm{Cp}^{+}$and ${ }^{-}$the opening coefficient of pressure [-], $\mathrm{c}_{\mathrm{d}}$ the discharge coefficient of each opening [-] and A the net opening area $\left[\mathrm{m}^{2}\right]$. ACH can be calculated by reporting $\mathrm{q}$ to hourly airflow rate and by diving this last value by space volume.

The presence of trees affects nocturnal ventilation only in the case of Quercus Ilex (Pinus Pinaster does not generate any blockage effect on the façade). For Quercus Ilex trees, the first floor apartment is supposed to experiment an increase in $\mathrm{ACH}$ of $20 \%$. The second floor apartment is supposed to experiment a reduction in $\mathrm{ACH}$ of $50 \%$, however more detailed field studies are needed to establish the effective change in real cases.

Table 6: Nocturnal ventilation summer value for Quercus Ilex configurations in each apartment

\begin{tabular}{|l|c|c|c|c|c|c|c|c|}
\hline & \multicolumn{7}{|c|}{ Ach $\left(\mathbf{h}^{-1}\right)$} \\
\hline & 11 & 12 & 13 & 14 & 21 & 22 & 23 & 24 \\
\hline Base & 1 & 1 & 1 & 1 & 1 & 1 & 1 & 1 \\
\hline Case1 & 1.2 & 1.2 & 1.2 & 1.2 & 0.75 & 0.75 & 0.5 & 0.5 \\
\hline Case2 & 1.2 & 1 & 1 & 1.2 & 0.75 & 1 & 1 & 0.5 \\
\hline Case3 & 1 & 1.2 & 1.2 & 1 & 1 & 0.75 & 0.5 & 1 \\
\hline Case4 & 1.2 & 1.2 & 1.2 & 1.2 & 0.75 & 0.75 & 0.75 & 0.75 \\
\hline Case5 & 1.2 & 1 & 1 & 1.2 & 0.75 & 1 & 1 & 0.75 \\
\hline Case6 & 1 & 1.2 & 1.2 & 1 & 1 & 0.75 & 0.75 & 1 \\
\hline Case7 & 1 & 1 & 1.2 & 1.2 & 1 & 1 & 0.75 & 0.75 \\
\hline
\end{tabular}

As noticed by some researchers (Kitahara et al., 2016), wind blockage effect of green areas can be determinant on building energy performance and should be taken into consideration. If a detailed simulation of air movement around a building is very complicated to be conducted, the simple statements of above should generate a result that partially balances the positive and negative effects of trees on reducing the overheating and helping the application of passive cooling strategies. In the simplified simulation, wind direction has been unchanged in weather data, while wind velocity has been reduced or increased depending on the building geometry. 


\section{Results}

Simulations have been carried out for the whole Typical Meteorological Year. For the base case of the analysed building a heating demand of $3.48 \mathrm{kWh} / \mathrm{m}^{2}$ and a cooling demand of $28.30 \mathrm{kWh} / \mathrm{m}^{2}$ have been assumed in accordance to the climatic features and building technologies in Sicily. Even if the traditional stonemasonry buildings show a good thermal comfort in summertime, most of buildings stock in Sicily require more cooling energy than heating energy. This is due to the longer summer time period characterised by high temperatures (from June to September) than the winter, when the very low temperatures are limited to a shorter period time (from January to mid of February). Considering the impact of green infrastructure on thermal demands of this kind of buildings, it can be assumed that the combined effect of shadow, sky view factor reduction, changes in convection and air movement result in an energy saving of at least 20\%. Figures 9 and 10 show the simulation results for the seven configurations of trees tested, for both trees typologies. By using Pinus Pinaster, the energy saving obtained is more than $50 \%$ in the configuration 1 (trees on east, west and south façades of the test building). Configuration 4 (trees on east and west façades) provides a saving of about $40 \%$. Quercus Ilex results are a little worse: $35 \%$ of saving in configuration 1 and $33 \%$ in configuration 4 . The reason of the different behaviour of this kind of tree is the reduced height (six meters) that impedes the roof's shadowing. Actually, the improvement in Pinus Pinaster configuration obtained by placing trees on the southern façade (shifting from configuration 4 to configuration 1) is due to the increase of the roof's protection from incoming solar radiation. As the case of Quercus Ilex put in evidence, there is almost no benefit in shadowing the southern façade itself. This result is perfectly understandable by analysing solar diagrams: the southern façade is exposed in winter and in intermediate season but not in summer.

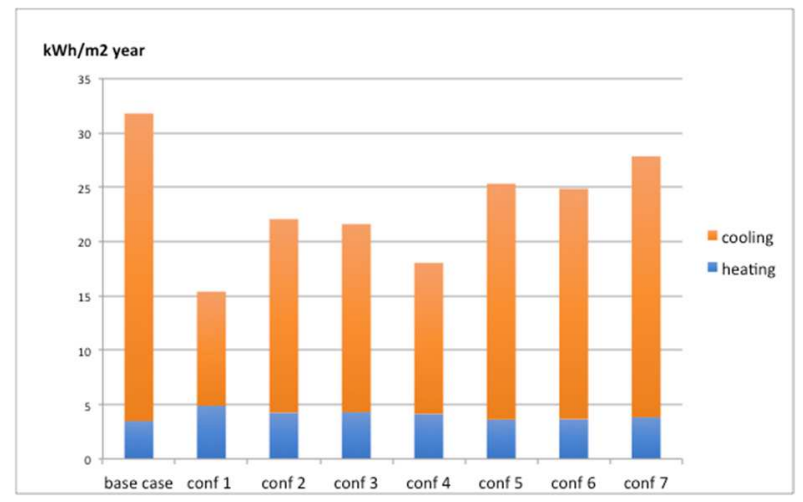

Figure 9: Results for Pinus Pinaster

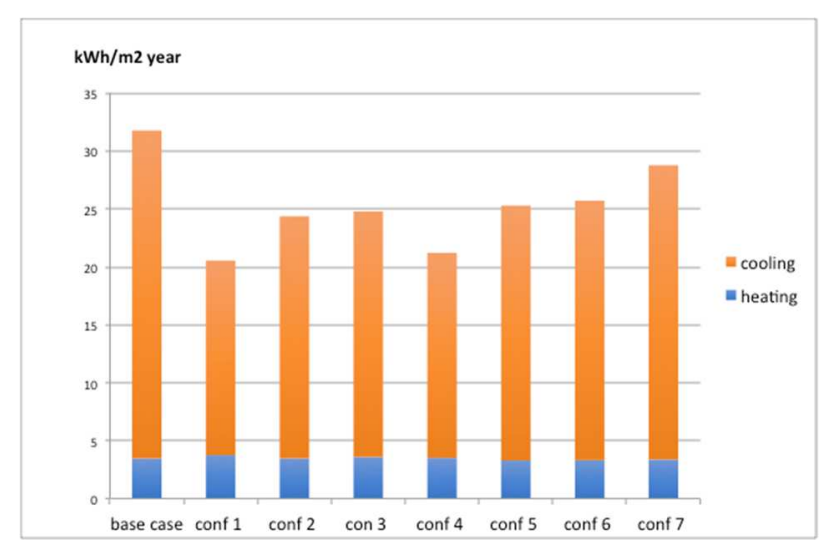

Figure 10: Results for Quercus Ilex

Another important outcome is that the combination of effects (shadows, air movement) results in a net energy saving, this means that the shadow effect is absolutely more important than the reduction of free cooling for Catania's climate conditions in where, for the majority of hours, the environmental air temperature remains too high to cool spaces even during night time. Figure 11 exposes the result of shadows and wind reduction for the Quercus Ilex case. With used ach values, wind reduction effect is less than $10 \%$ in each case and less than $1 \%$ in some.

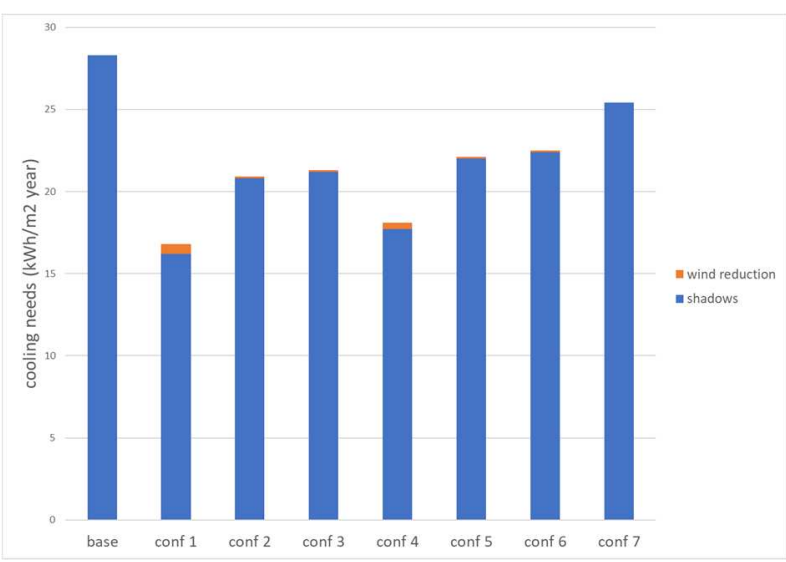

Figure 11: cooling needs for Quercus Ilex, showing the effect of shadows and air change per hour reduction

In the case of Pinus Pinaster, where no changes in ach is considered, the reduction (in presence of trees) of the convective coefficients of roof surfaces lead to an absolutely negligible effect. However, it has to be considered that assumption in ach changes is a very strong simplification. ACH could vary between 0 and more than 50 volumes per hour in natural cooling. Further studies should be conducted to indicate the real influence that air speed reduction can have on summer cooling performance. 


\section{Discussion and conclusion}

The simulations developed in the work allowed to identify those configurations that limit the number of trees to be planted and that, therefore, represent more economical solutions in terms of required financial resources. As a general recommendation, trees selection should be conducted considering the form and especially the height of trees. Pinus Pinaster configurations show a better behaviour because permit to shadow the roof of small buildings and don't generate any blockage effect of wind on facades. However, the complex arrangement between buildings, other built-up areas and open spaces represent an innovative topic of research and require more specific studies to characterise the parameters that could play a role in the choice of the most effective configuration of trees. These parameters include: the shape and height of the buildings, an advanced analysis of wind-flows including tree porosity, the available distances from the building where to plant the trees, the orientation of the trees and relative species. Preferences for tree species should be oriented to ones able to shade the entire facades and, therefore, maximise the reduction of energy demand: to this end, deciduous trees allowing for solar gain during the wintertime could be preferred, yet differences in cooling effects can be observed among different species. Despite the highlighted cooling potentiality, the implementation of a public GI in urban environments faces several difficulties and limitations for its real development and management, especially in dense urban contexts. In urban contexts similar to the one considered in this paper, residential compounds with multi-storey buildings and several landowners represent potential areas for new greenery and GI, as they present different proportions and spatial arrangements of built-up areas and shared open spaces (fig. 1). However, one of the most relevant limitation is the public acquisition of the land where the GI can be designed and implemented, as municipalities or other public bodies often do not own this land and have no economic resources to buy it from private landowners (Bengstone et al., 2004).

Transfer of Development Rights programs represent one of the most used strategy to ensure the economic feasibility of such public interventions and therefore acquire public green spaces (Nelson et al., 2012). Recently, Privitera and La Rosa (2018) proposed a scenario in which landowners of the compounds leave portions of shared open spaces to public property and obtain, as a compensation, an equitable amount of development rights to be sold to developer within a Transfer of Development Right Program. With the economic earnings obtained from the sale of these development rights, the landowners of the compounds can be able to fund seismic retrofitting interventions of the buildings in the same compound. Local municipalities can acquire some open spaces in the compounds without financial efforts and implement a new green infrastructure. To close the circle, the buildings included in the compound would economically benefit from the cooling capacity of the new GI mainly through shading effect. Such a multi-benefits and multi-scale strategy, acting from municipal level to building level, would contribute to regenerate vulnerable and inefficient portions of the city and increase the number and quality of ecosystem services provided by the new GI.

\section{Acknowledgement}

This work received the support of the Visiting Researcher programme of the University of Catania.

\section{References}

Berry, R., Livesley, S., Aye, L. (2013). Tree canopy shade impacts on solar irradiance recived by building walls and their surface temperature. Building and Environment 69, 91-100

Balogun, A.A.; Morakinyo, T.E.; Adegun, O.B. (2014). Effect of tree-shading on energy demand of two similar buildings. Energy and Buildings 81, 305-315.

Bengston, D.N.; Fletcher, J.O.; Nelson, K.C. (2004). Public policies for managing urban growth and protecting open space: Policy instruments and lessons learned in the United States. Landscape and Urban Planning 69, 271-286.

Calcerano, F., Martinelli, L. (2016). Numerical optimization through dynamic simulation of the position of trees around a stand-alone building to reduce cooling energy consumption. Energy and Buildings 112, 234-243

Cantón, M. A., Cortegoso, J. L., de Rosa, C. (1994). Solar permeability of urban trees in cities of western Argentina. Energy and Buildings 20, 219-230

Correa, E., Ruiz, M. A., Canton, A., Lesino, G. (2012). Thermal comfort in forested urban canyons of low building density. An assessment for the city of Mendoza, Argentina. Building and Environment 58, 2019-230

Fan, P.; Ouyang, Z.; Basnou, C.; Pino, J.; Park, H.; Chen, J. (2017). Nature-based solutions for urban landscapes under post-industrialization and globalization: Barcelona versus shanghai. Environonmental Research 156, 272-283.

Givoni, B. (1991). Impact of planted areas on urban environmental quality: A review. Atmospheric. Environment 25, 289-299.

Grosso, M. (2003). Il raffrescamento passivo degli edifici. Maggioli Ed.

Kitahara, T., Takagi, N., Marui, M. (2016). The effect of wind speed reduction by trees in green spaces on temperature. Proceedings of the 4th International Conference on Countermeasures to Urban Heat Island, 30-31 May and 1 June 2016, National University of Singapore, Singapore.

Konarska, J., Lindberg, F., Larsson, A., Thorsson, S., Holmer, B. (2014). Transmissivity of solar radiation through crowns af single urban trees - application for outdoor thermal comfort modelling. Theoretical and Applied Climatology 117 (3-4), 363-376 
Konarska, J., Uddling, J., Holmer, B, Lutz, M., Lindberg, F., Pleijel, H., Thorsson, S. (2015). Transpiration of urban trees and its cooling effect in a high latitude city. International Journal of Biometereology 60 (1), 159172

Hagishima, A. and Tanimoto, J. (2003). Field measurements for estimating the convective heat transfer coeffcient at building surfaces. Building and Environment 38, 873-881

Hsieh, C.H.; Li, J.J.; Zhang, L.; Schweglerd, B. (2018). Effects of tree shading and transpiration on building cooling energy use. Energy and Buildings, 159, 382397.

Laband, D.; Sophocleus, V. (2009). An experimental analysis of the impact of tree shade on electricity consumption, Arboriculture and Urban Forestry 35, 197-202.

McPherson, E., Xiao, Q., van Doorn, N., Johnson, N., Albers, S., Peper, P. (2018). Shade factors for 149 taxa of in-leaf urban trees in the USA. Urban Forestry \& Urban Greening 31, 204-2011

Nelson, A.C.; Pruetz, R.; Woodruff, D.; Nicholas, J.C.; Juergensmeyer, J.C.; Witten, J. (2012). The TDR Handbook-Designing and Implementing Transfer of Development Rights Programs; Island Press: Washington, DC, USA

Nesshöver, C., Assmuth, T., Irvine, K.N., Rusch, G.M., Waylen, K.A., Delbaere, B., Haase, D.; JonesWalters, L., Keune, H., Kovacs, E., et al. (2017). The science, policy and practice of nature-based solutions: An interdisciplinary perspective. Scienze of the Total Environment 579, 1215-1227.
Palme, M., Inostroza, L., Salvati, A. (2018). Technomass and cooling demand in South America: A super linear relationship? Building Research and Information 46 (8), 864-880

Palme, M., Inostroza, L., Villacreses, G., Lobato, A., Carrasco, C. (2017). From urban climate to energy consumption. Enhancing building performance simulation by considering the urban heat island effect. Energy and Buildings 145, 107-120

Pappalardo, V., La Rosa, D., Campisano, A., La Greca, P. (2017). The potential of green infrastructure application in urban runoff control for land use planning: A preliminary evaluation from a southern Italy case study. Ecosystem Services 26, 345-354.

Privitera, R., La Rosa, D. (2018). Reducing Seismic Vulnerability and Energy Demand of Cities through Green Infrastructure. Sustainability 10(8): 2591

Palme, M., Salvati, A. (2018). UWG - TRNSYS simulation coupling for Urban Building Energy modeling. Proceedings of the Building Simulation and Optimization Conference, Cambridge, UK, 11-12 September 2018

Tzoulas, K., Korpela, K., Venn, S., Yli-Pelkonen, V., Kazmierczak, A., Niemela, J., James, P. (2007). Promoting ecosystems and human health using green infrastructure: A literature review. Landscape and Urban Planning 81, 167-178.

Wild, T.; Henneberry, J.M.; Gill, L. (2017). Comprehending the multiple 'values' of green infrastructure-valuing nature-based solutions for urban water management, from multiple perspectives. Environmental Research 158, 179-187. 